\title{
INTRODUCTION OF PODCASTS IN REMOTE SENSING EDUCATION
}

\author{
Raffaella Guida
}

\author{
Surrey Space Centre, University of Surrey, Guildford, UK
}

\begin{abstract}
This paper deals with a new teaching experience carried on at the Department of Electronic Engineering at University of Surrey. The experience is based on the enhancement of students learning in the Satellite Remote Sensing class with the adoption of new technologies for assessment and teaching purposes.

More precisely, podcasts have been introduced in a 3year long project as supporting teaching material or coursework.

Here the experience of the first year, where podcasts are introduced as group coursework, is described in detailed and commented.
\end{abstract}

Index Terms - Education, remote sensing, podcast.

\section{INTRODUCTION}

Education constantly presents new challenges. Currently, one of the most interesting is to find appropriate medium to communicate and share knowledge with new generations.

New technologies may offer ways to address this challenge. Blogs, wikis, podcasts [1-2] are just some of the latest and most innovative technologies which are pervading the free time of young people. Indeed, although within academic environments they are often considered not serious or reliable instruments for education, they have captured the interest of new generations, such as those looking on the web for people to communicate with or those unable to move without their iPod.

Remote Sensing is a relatively young subject that always generates interest among students, naturally concerned with the earth's future and fascinated by the idea of monitoring the conditions of its resources. As a scientific subject, remote sensing often needs mathematics and physics theories as support to its teaching. Moreover, the showing of images acquired by different sensors is valuable to develop students' experience.

This paper deals with a completely new and innovative approach applied in the remote sensing class at the Department of Electronic Engineering, University of Surrey, in order to enhance the teaching and learning of remote sensing by means of podcasts, [2].

In particular, in this paper the author describes the experience got in the first year of a three-year project at University of Surrey in which Podcasts are introduced as part of the assessment (1st year) and supporting material to the lectures (2nd and 3rd year) in the Satellite Remote Sensing class.

\section{PODCASTS FOR COURSEWORK}

Podcasting refers to the method of timely delivery of content to people, students in this case, who have selected to 'subscribe' to receive the content. Podcasts files can be produced in a variety of formats, the main ones being: audio-only, audio with images (called 'enhanced') or video recordings. For this remote sensing class, audio-only formats were considered to be unlikely to capture the interest and attention of students, even if is the simplest format to produce.

One reason for exploring podcasts in this project is their portability which allows students to learn at opportune moments such as when travelling on a bus and teachers to assess without carrying lots of heavy papers and scripts everywhere.

The students were asked to prepare a Podcast (preferably in video or enhanced format) on Monitoring Earth's resources with Remote Sensing. In this they were asked to describe and comment, in no more than 10 minutes, on a remote sensing application in a field of their interest to be chosen from among some given in a list.

In the Podcast they were asked to cover the following:

1. Why your application needs remote sensing techniques 2. Which particular sensors are successful for your application and why

3. The most interesting results achieved in current literature

4. The present limits and the future challenges

Asking the students to produce something "popular" and not highly technical which could communicate and transfer a concept to everyone compelled them to think, discuss and debate about the most suitable 
words/video/time/pauses to transfer that particular concept. They had to think like a lecturer while preparing for the class.

To package the podcast the students had to learn the software Camtasia Studio 6.0 [3] which they downloaded and installed the 30-day trial version. Camtasia is a really powerful software enabling the recording of on screen activity and editing this into a polished video that can then be shared.

In the final step, the students were asked to convert their Camtasia final product in a format compatible with iPod touch or iPhone device (.mv4). Consequently some requirements were also given to them in terms of the minimum text height, quality and size of the image.

At the conference the best Podcasts the students realized will be shown.

\section{OUTCOME}

Twenty six students worked on podcasts as part of this project. They were encouraged to work in small groups and were allowed to choose their own teams. Three of them worked alone (two were students who needed to resit so could not attend the lectures and the other was a student who joined the class when the other groups were already formed). The other 23 split into one pair and 6 groups of 3 or 4 people.

Three very good podcasts were produced on the application of remote sensing in: agriculture, forest and geology. In the agriculture podcast, for example, the students used a mix of original video recordings of agricultural scenes (they even flew a glider to capture the aerial pictures) and represented themselves acting the roles of a farmer and a remote sensing expert giving advice. They also included Power Point slides for summarizing and remote sensing images with running commentary. (see Figure 1). The final result was really enjoyable.

Another interesting podcast which was also original in its format was on archaeology applications. In this example the students based the podcast on a comic-strip story drawn by themselves with off-screen voices. The idea was obviously based on a very famous movie character. Also in this podcast, remote sensing images were extensively discussed which was good as they showed the ability to present a scientific subject in a popular format. On the other hand, the pace of pictures was a bit slow which resulted in a quite static podcast. This is likely to be due to the difficulty in drawing many strips.

\section{STUDENTS FEEDBACK AND REFLECTIONS}

The author prepared and submitted a questionnaire to students at the fourth lecture. Students' feedback on this project was really useful to understand what needs to be changed or improved.
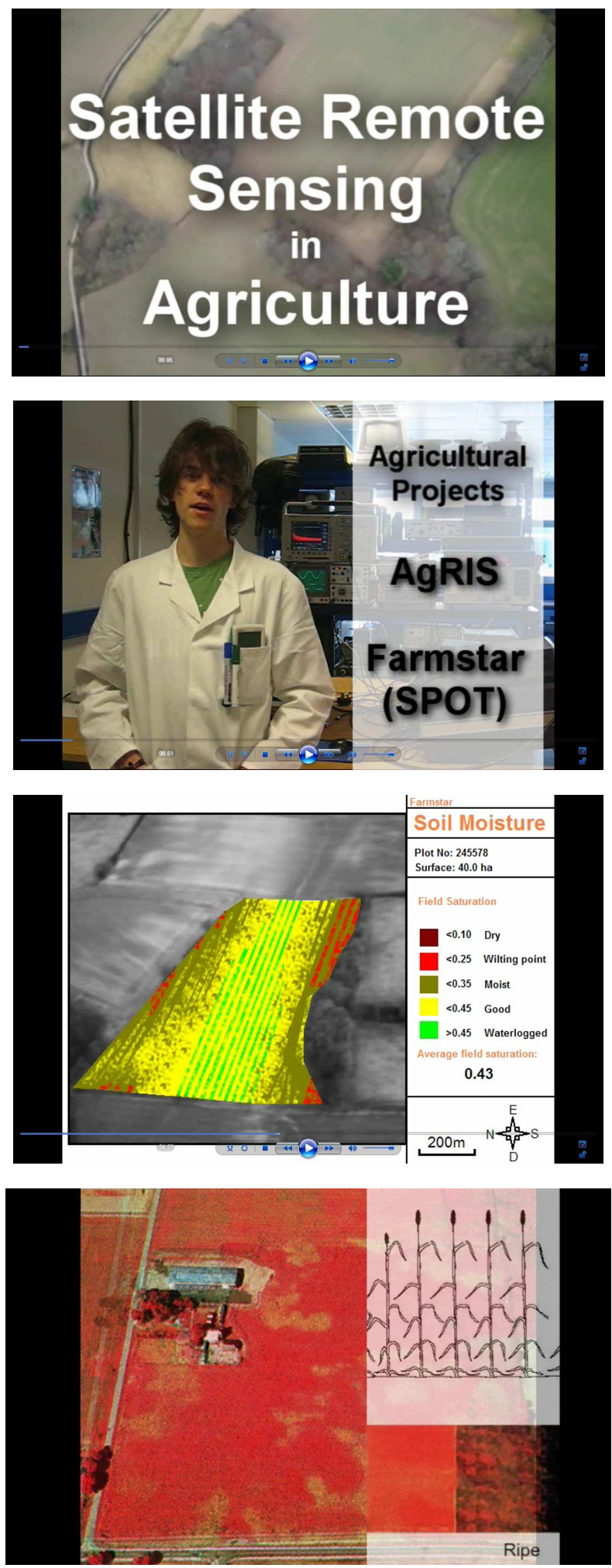

Figure 1 - Some frames of the Podcast in Satellite Remote Sensing in Agriculture 
In the first year of the project the class was generally happy with this new kind experience even if many students considered the coursework very time consuming. Others asked to receive feedback not only at the end of the packaging but also during the intermediate steps and, indeed, this has been introduced in the second year of the project. Some students asked to have better explanation about what is expected to be submitted. A few considered the experience boring, all coming from postgraduate courses since this module is open to both undergraduate and postgraduate students.

Further feedback arrived at the end of the module by the module evaluation questionnaire prepared by the University and the Department of Electronic Engineering which confirmed the considerations above.

All the feedback has been considered to improve the coursework in the second year of the project and indeed the percentage of students who found it an interesting experience definitely increased .

\section{BENEFITS AND PROBLEMS}

This experience helped students to engage with and reflect on the module content, therefore ensuring that they don't forget everything after the end of the module.

It can produce material that is of sufficiently high quality that it can be recycled, further improved, and delivered to future students as supporting material as happened in some cases in this pilot.

Works like this can let tutors discover how creative and original students can be, an aspect that is harder to assess in standard procedures of assessment.

Although the class was alerted that feedback would be given to them only in the final stage, some of them complained about this and asked to have feedback after each stage and this has been considered in the second year of the project.

Preparation of podcasts was time consuming and the students asked to have it weighted more than $30 \%$ (as it is at the moment).

There were also copyright issues. For example it was hard to find free music on the web but some further suggestions on this came from the e-learning team at University of Surrey. Some students used well known movies soundtrack which make their podcasts unsuitable as copyright laws would be infringed. Free video/images can be found more easily but when used need to be properly attributed.

In one group students complained that other members did not really contribute to the podcast preparation. A form for assessing individual contribution to group work is therefore considered necessary to solve the matter and recognize every member's effort.

\section{CONCLUSIONS}

This project has been run again in the last academic year with a few changes and some improvements. This year the best podcasts that the students prepared in the first year have been circulated. In this way the students had a better idea of what they were expected to prepare and this improved the overall experience.

In the following some conclusive remarks/advice are given to colleagues interested in proposing a similar experience to their class:

- It is good for group projects and for large numbers of students;

- It reduces the time for assessing and marking coursework;

- It is highly portable, you can assess everywhere in every moment;

- It is suitable for other subjects "not only math";

- It works even better in undergraduate classes where students are often less suspicious in respect of novelty but much more well-disposed to try new things;

- Precise deadlines and times are needed at each step;

- A marking scheme able to assess both the group effort and the individual contribution is necessary. In this case, students need to be advised at the beginning of the class that, even if they work in a group, individual contribution will be assessed in order to encourage everyone to contribute;

- Instructions about the software for the final packaging are required;

- Notes on podcast preparation specifying everything, from what is expected to how to do it, are warmly encouraged.

To the best of my knowledge, the experience carried on at University of Surrey, i.e. the production of remote sensing podcasts, is without precedent. Moreover, podcasts' quality of giving new life to subject matter suggests the adoption of new technologies everywhere is possible for enhancing the learning experience. Its portability particularly encourages its diffusion in countries where everyday students have to face long commutes.

\section{ACKNOWLEDGEMENTS}

The author thanks the e-learning team at University of Surrey for awarding this project with the Teaching with New Technologies (TeNT) award.

\section{REFERENCES}

[1] W.Richardson, Blogs, Wikis, Podcasts, and Other Powerful Web Tools for Classrooms, Corwin Press, 2006.

[2] R.Harrington, M.Weiser, Producing Video Podcasts: A Guide for Media Professionals, Elsevier, 2008

[3] http://www.techsmith.com/camtasia.asp 